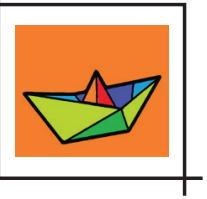

\title{
MIGRAÇÃO E MISSÃO NA ASSEMBLEIA DE DEUS NO, BRASIL: DOS MISSIONÁRIOS SUECOS AOS MISSIONÁRIOS BRASILEIROS, UMA JORNADA MIGRATÓRIA NO PENTECOSTALISMO ASSEMBLEIANO
}

\author{
Jimmy Barbosa Pessoa* \\ Edin Sued Abumanssur**
}

Resumo: 0 presente trabalho busca apresentar como a migração sempre fez parte da história da Igreja Assembleia de Deus no Brasil, por meio de uma introdução do percurso histórico da maior denominação pentecostal no mundo, trazendo um breve relato da vinda dos missionários suecos a Belém, Pará, e da chegada de outros obreiros e obreiras de outras nacionalidades para cooperar na missão da implantação da Assembleia de Deus em outros estados e no interior da Região Norte do pais e no envio de missionários brasileiros para outras nacionalidades, a fim do cumprimento da grande missão. Realizamos, assim, uma análise histórica e sociológica da presença da migração no meio pentecostal até a contemporaneidade, pois, por meio desses fundamentos históricos, se construíram as bases para o trabalho contemporâneo das missões assembleianas presentes em todos os cantos do mundo. Esta pesquisa tem sua importância por apresentar aos líderes, aos membros dessa denominação e aos estudantes e pesquisadores maior compreensão sobre o assunto da migração. Isso é fundamental para a valorização de cada pessoa que deixa sua terra natal e migra para outro pais por motivos diversos e para a conscientização sobre a conduta do hospedeiro, que deve sempre ser baseada no acolhimento, compreensão e apoio, pois todos os grupos têm marcas da migração em seus percursos históricos.

Palavras-chave: Migração. Missionários. Assembleia de Deus. Pentecostalismo. Migrante.

\section{INTRODUÇÃO}

0 presente trabalho busca tratar da origem da Assembleia de Deus (AD) a partir do trabaIho de missionários estrangeiros que chegaram ao Brasil e aqui iniciaram uma das maiores

\footnotetext{
* Doutorando em Psicologia Social e do Trabalho pela Universidade de São Paulo (USP). Metre em Ciência da Religião pela Pontifícia Universidade Católica de São Paulo (PUC-SP). E-mail: jimmypessoa@usp.br

** Doutor em Ciências Sociais pela Pontifícia Universidade Católica de São Paulo (PUC-SP). Docente do Programa de Estudos Pós-Graduados em Ciência da Religião da PUC-SP.E-mail: edin@pucsp.br
} 
denominações pentecostais do mundo. Rompendo com os desafios do idioma, da cultura, do clima, do preconceito religioso e da política nacionalista que perdurou por muitos anos, fundaram a igreja de confissão pentecostal, expandiram para o interior e realizaram um trabalho que marcou a história não apenas da denominação, mas do país.

Trataremos ainda da importância da religião, da compreensão sobre o cuidado com o estrangeiro, da mensagem do pentecoste, que tem em sua essência a universalidade da missão cristã, e de uma reflexão sobre não aceitar ideologias que incentivam a xenofobia e os conceitos preconceituosos contra os estrangeiros. Sendo assim, considera-se um dever da Igreja AD o cuidado e acolhimento com os estrangeiros que chegam às terras brasileiras, pois um dia os seus fundadores estiveram sob as mesmas circunstâncias.

Este trabalho foi elaborado a partir de pesquisas bibliográficas e alguns diálogos com pessoas ligadas a atividades missionárias. Buscou-se realizar uma análise da vida dos missionários suecos que iniciaram e fundaram a $A D$ no início do século XX, como também foram citados os nomes de outros missionários e missionárias que contribuíram na expansão da denominação pentecostal. 0 trabalho desses pioneiros, mesmo enfrentando dificuldades e empecilhos, marcou o seu tempo e, por meio de suas histórias, a Igreja no Brasil organizou uma grande agência missionária que envia homens e mulheres para todas as partes do mundo.

0 percurso histórico da AD é marcado em todos os estados do Brasil pela presença de missionários estrangeiros e nacionais, pois, seja migração interna ou externa, migração e missão sempre caminharam juntas, e viver a lgreja é viver em fraternidade, a paz e o amor entre todos, sem distinção de etnia, grupo, nação ou cultura.

\section{OS MIGRANTES FUNDADORES DE UMA IGREJA BRASILEIRA}

Assim como toda instituição, a AD tem uma origem que é preponderante para sua história, influenciando na formação dos membros, liderança, organização e perspectivas. 0 movimento pentecostal assembleiano teve início no Norte do Brasil, na cidade de Belém, no Pará. No meio da Floresta Amazônica são semeadas as primeiras mensagens da fé pentecostal.

A Igreja $A D$ é resultado do trabalho de dois missionários suecos que haviam participado do movimento pentecostal nos Estados Unidos e, influenciados pelo que eles chamavam de orientação divina, partiram para o Brasil com o propósito de iniciar um trabalho missionário. Os dois missionários chamavam-se Gunnar Vingren e Daniel Berg. Em um diário, Vingren (2017, p. 27) afirma que: "Um outro irmão, Adolfo Ulldin, recebeu do Espírito Santo palavras maravilhosas, e vários mistérios sobre o meu futuro lhe foram revelados. Entre outras coisas, o Espírito Santo falou através desse irmão que eu deveria ir para o Pará".

A mensagem sobre a vinda para o Brasil é recebida por Vingren (2017), que escreve em seu diário que foi necessário saber onde era essa terra chamada Pará, a qual ele não conhecia e 
nem sabia que existia. No dia seguinte declarou ao irmão, Adolfo: "Vamos a uma biblioteca aqui na cidade para saber se existe algum lugar na Terra chamado Pará. Nossa pesquisa nos fez saber que no Norte do Brasil havia um lugar com esse nome" (VINGREN, 2017, p. 27-28).

No ano de 1909, Vingren conhece Daniel Berg, tornam-se muito amigos e, em 1910, Berg vai cooperar com ele no trabalho de evangelização na cidade de South Bend, auxiliando nos cultos e nas atividades da Igreja (VINGREN, 2017). Essa amizade dos dois, iniciada nos Estados Unidos, faz que se estabeleça uma relação que se estende até o fim da vida dos missionários.

Após um tempo de trabalho na América do Norte, os dois partem para o Brasil, no dia 5 de novembro de 1910, desembarcando em terras tupiniquins no dia 19 de novembro de 1910. 0 navio que os trouxe se chamava Clement. 0 navio ficou fora do porto e uma pequena embarcação os trouxe até o cais (VINGREN, 2017). Após um tempo cooperando na igreja batista em Belém, os missionários suecos e outros 18 membros da comunidade Batista, por crerem na evidência do falar em línguas e na contemporaneidade dos dons, são excluídos da respectiva denominação evangélica. Então, fundam a missão apostólica da fé em 1911, a qual, posteriormente, se chamaria AD.

0 movimento assembleiano cresceu e teve início em muitas cidades com o trabalho de missionários da Europa e dos Estados Unidos que desembarcaram no Brasil no início do século XX. A maioria deles escolheu os centros urbanos para serem as primeiras terras para a implantação das igrejas pentecostais antes de alcançarem o resto do país. Expandindo-se pelas capitais dos estados que estão, em sua maioria, no litoral, as congregações foram estabelecidas e as cidades passaram a receber seus novos moradores, que falavam português com sotaque estrangeiro e cuja aparência era nitidamente diferente da aparência dos brasileiros, mas buscaram se integrar a esse povo e aqui construir suas histórias, que marcaram gerações.

No Brasil, dezenas de missionários e missionárias atuaram nas cidades e nos trabalhos de implantação de igrejas e na organização da denominação. Citamos na Tabela 1 alguns dos nomes desses homens e mulheres que desempenharam a tarefa de evangelização em terras brasileiras. 
Tabela 1 Relação de alguns missionários que fundaram a AD no Brasil

\begin{tabular}{cccc}
\hline Missionário & País de origem & Missionária & País de origem \\
\hline Gunnar Vingren & Suécia & Frida Vingren & Suécia \\
\hline Daniel Berg & Suécia & Sarah Berg & Suécia \\
\hline Samuel Nystro & Suécia & Lina Nystron & Suécia \\
\hline Joel F. Adolf Carlson & Suécia & Signe Hedlund & Suécia \\
\hline Algot Svensson & Suécia & Rosa Svensson & Suécia \\
\hline Bruno Skolemowsky & Polônia & Anna Carlsson & Suécia \\
\hline Climaco Bueno Aza & Colômbia & Andrea G. Magnusson & Suécia \\
\hline Otto Nelson & Suécia & Andina Petterson & Suécia \\
\hline Nils Kastberg & Suécia & Eufrosyne & Suécia \\
\hline Nels Lawrence Olson & Estados Unidos & Alice Lawrence Olson & Estados Unidos \\
\hline Bernhard Johnson Jr & Estados Unidos & Doris Buckett & Estados Unidos \\
\hline Orlando S. Boyer & Estados Unidos & Ethel Boyer & Estados Unidos \\
\hline
\end{tabular}

Fonte: Elaborada pelos autores.

Os missionários e missionárias, além do trabalho religioso, desempenharam uma missão social junto às comunidades onde estavam instalados, visitando delegacias, hospitais, cuidando de órfãos, distribuindo comida, dando assistência a idosos e idosas, ensinando alguns novos convertidos a ler, escreveram livros e fundaram jornais. Eles sempre buscaram apoiar as igrejas que frequentavam no cumprimento da missão a que eles haviam dedicado suas vidas, como deixaram escrito ou como foi registrado por outros membros da AD.

A maior denominação pentecostal e evangélica do Brasil nasceu como fruto do trabalho de homens e mulheres que migraram para uma terra de altas temperaturas e que ainda se encontrava em um processo de desenvolvimento. Enfrentaram todos os desafios de um processo migratório, que estão atrelados a questões políticas, perseguição religiosa, dificuldade de compreensão por causa do idioma, alimentação e cultura diferentes das de sua formação, preconceito contra estrangeiros e muitos outros fatores com os quais os imigrantes lidam.

Uma situação que pode ser destacada entre as dificuldades encontradas pelos missionários ocorreu em setembro de 1930, na primeira convenção geral da AD em Natal, no Rio Grande do Norte. Os missionários, por determinação dos pastores brasileiros, que exigiam autonomia e independência dos pastores estrangeiros, passam a liderança da maioria das igrejas do Norte e Nordeste do Brasil para pastores brasileiros. Muitos obreiros americanos, suecos e de outras nacionalidades migraram para o Sudeste e Sul do território brasileiro (ALENCAR, 2010). Nesse período, o Brasil está sob uma efervescência nacionalista, com uma revolução que aconteceria em outubro e firmaria Getúlio Vargas no poder por cerca de 15 anos (COSTA; MELLO, 1999). Este sentimento nacionalista parece ter adentrado nas igrejas 
assembleianas, fazendo com que os missionários fundadores fossem convidados a se retirar mais uma vez de uma comunidade evangélica. Mas, agora, das próprias comunidades religiosas que fundaram.

Conforme os registros bibliográficos, os aparentes motivos para a busca de maior autonomia por parte dos pastores nacionais são frutos do desejo de assumir a liderança da denominação e dirigirem os trabalhos da igreja no Brasil. Um exemplo é o pastor Cícero Canuto de Lima ter presidido a reunião de 1930, quando estavam presentes pastores estrangeiros de maior experiência e profunda atuação na denominação. Como Gunnar Vingren, o fundador da igreja e Samuel Nyström, que já possuía anos de pastorado. Podemos afirmar que existia um temor de uma possível cisão na Igreja por conta deste sentimento de exaltação nacional, como escreve Lewi Pethrus em sua biografia, na qual elenca a questão política nacionalista em vigência no Brasil (DANIEL, 2004).

Todo preconceito ou xenofobia, estimulado por ideologias políticas ou ideias de grupos de supremacia nacionalista, destoa e contradiz a mensagem bíblica, além de ser uma negação da história da igreja AD e do cristianismo como um todo. A Assembleia de Deus foi fundada, organizada e amada por homes e mulheres de outras pátrias, mas que amaram o Brasil profundamente, entregando suas vidas à missão em terras brasileiras. Visitando hospitais, cadeias, bairros periféricos, vielas e vilas. Indo aos sertões, florestas e ilhas para implantar igrejas e levar a mensagem de amor, paz e vida.

\section{A MIGRAÇÃO MISSIONÁRIA: O ENVIO DE MISSIONÁRIOS BRASILEIROS AO EXTERIOR}

Ainda muito recente o início do trabalho da missão pentecostal sueca no Brasil, Gunnar Vingren envia o primeiro missionário para Portugal. Eles foram os fundadores da denominação em todo o solo brasileiro, com o apoio de pastores estrangeiros, e enviaram os primeiros missionários para solo internacional com a tarefa de evangelização. 0 missionário designado para Portugal, em 1913, foi José Plácido da Costa, com o objetivo de implantar a Igreja no país. Posteriormente, outros missionários, junto com suas famílias, seguiram para outras terras com o mesmo objetivo de seus irmãos.

Até a década de 1970, as Igrejas Assembleias de Deus no Brasil não possuiam um órgão credenciado para a organização do trabalho missionário em nível nacional com fim de implantação de igrejas da AD em outros países.

Essa situação perdurou até janeiro do ano de 1975, quando na 22a Convenção Geral das Assembleias de Deus no Brasil na cidade de Santo André - SP, no dia 22 de janeiro nasceu a SENAMI - Secretaria Nacional de Missões da CGADB, com a finalidade de estruturar o 
trabalho missionário da denominação no Brasil e no exterior e credenciar os missionários enviados por suas igrejas (CONRAD0, 2019).

Desde sua origem em 1975, a Secretaria Nacional de Missões (Senami) tem buscado organizar um trabalho junto às convenções filiadas, incentivando a formação e estruturação de secretarias de missões, cursos e reuniões com secretários dos estados de todas as regiões do Brasil e mantém uma rádio web que tem programas diários e serve como canal de comunicação com os missionários em todos os paises do mundo.

Durante esses 44 anos de atividade, a SENAMI tem espalhado a mensagem do Evangelho, atualmente em mais de 52 paises, 26 estados do Brasil, com mais de 3.000 missionários ativos cadastrados em campo nacional e transcultural. As Secretarias de Missões cadastradas na SENAMI somam mais de 350, os missionários, atuando juntamente com as igrejas, realizam diversas ações sociais: restauração de vidas envolvidas nas drogas, educação infantil, implantação de novas igrejas, evangelização em aldeias indigenas, entre outros (CONRADO, 2019).

No final da década de 1980, inicia-se um movimento de preparação e envio de missionários das Assembleias de Deus brasileiras para vários paises do mundo. Ainda nessa década e na de 1990, os projetos missionários aumentaram e passaram a ser organizados em secretarias, recebendo siglas para a identificação das respectivas igrejas, campos, estados ou convenções. As igrejas foram incentivadas pela mensagem da grande ordenança registrada nos evangelhos, que diz: "Anunciai o Reino de Deus até os confins da Terra" (Mt 28.18-20; Mc16.15) e tiveram uma atuação ampla na realização de eventos que tratam do tema missão transcultural.

Por meio das conversas realizadas junto aos secretários de missões de alguns estados, com o intuito de obter informações sobre os trabalhos missionários desenvolvidos pelas secretarias de missões no envio de missionários, recebemos a informação de que os enviados podem ser um casal, em alguns casos, famílias, missionários jovens ou pessoas mais maduras solteiras. Esses recebem uma preparação sobre a cultura do pais onde eles residirão, idioma, curso básico de teologia, estudam missiologia e, atualmente, muitos já possuem curso superior e buscam, de alguma maneira, atuar na sua área de formação.

Seus objetivos transpõem-se às questões de proselitismo religioso, pois, além de buscarem novos adeptos, os missionários oferecem apoio social nas comunidades onde realizam a atividade. Essa assistência alcança os nativos da terra onde eles fixam suas residências e os de mesma nacionalidade que também migraram para o pais da missão. Muitas vezes, esse trabalho ocorre por haver um grupo de brasileiros já residindo no pais que solicita trabalho missionário. Isso pode acontecer por não haver outras igrejas ou por sentirem a necessidade de iniciar uma igreja de brasileiros naquele local. A comunidade é, então, um elo fortalecedor 
e de apoio aos que estão residindo ali, aos que chegam e a outros imigrantes que necessitam de informações e ajuda para se estabelecerem.

A missão assembleiana é herdeira de uma tradição missionária. Mesmo tendo sido iniciada com muitas limitações, os secretários de missões relataram-nos que os trabalhos realizados nas igrejas mantenedoras de missionários e missionárias avançou e avança nas questões do envio e sustento dessas pessoas.

A conscientização missionária é um trabalho que produz mudanças de percepção tanto nos migrantes brasileiros que vão ao campo missionário como nos membros das igrejas que enviam estes homens e mulheres. Os enviados, por meio da experiência de conviverem em terras estrangeiras, mudam suas percepções de enxergar os outros povos. Os fiéis que estão no Brasil, por meio das reuniões intituladas cultos de missões, assistem a vídeos e recebem estudos sobre o país escolhido para ser apresentado naquela reunião ou sobre a nação para a qual os migrantes religiosos foram enviados. É um momento do mês destinado ao que eles chamaram de conscientização missionária. 0 envio de missionários ao exterior é um trabalho constante das igrejas $A D$, seja na obra de evangelização no Norte e Nordeste brasileiro ou no trabalho que realizam em outros países. As atividades das secretarias de missões são amplas e contínuas. Um fato interessante que merece destaque é a unidade entre assembleianos e outras igrejas evangélicas nas atividades missionárias, pois, pelo cuidado com os missionários, eles rompem as cercas denominacionais e unem-se em prol do que chamam de "anunciar o Reino de Deus a todos os povos".

\section{O PENTECOSTES É A UNIDADE DE PESSOAS COM VÁRIAS LÍNGUAS E CULTURAS}

No livro de "Atos dos Apóstolos", capítulo 2, ocorre o que é conhecido na história e doutrina cristã como o derramamento do Espírito. 0 texto diz que todos que estavam no cenáculo (cômodo superior, como uma grande sala de uma residência, muito comum na época antiga) foram cheios do Espírito Santo e começaram a falar em outras línguas. No sentido de uma manifestação espiritual. Continuando o texto bíblico, ainda diz que homens e mulheres, judeus e gentios, e muitas pessoas que estavam em Jerusalém participando da festa do Pentecostes foram ver o que estava acontecendo, pois eles entendiam no seu próprio idioma o que falavam (At 2. 1-8).

0 conceito doutrinário e interpretativo do Pentecostes consiste no ajuntamento de pessoas, com diferentes idiomas, conceitos e práticas, considerado por hermeneutas uma restauração do que havia ocorrido na Torre de Babel - evento que é citado no capítulo 11 do livro "Gênesis" como o motivo da separação das línguas e dos povos. Sendo o Pentecostes a demonstração da universalidade da mensagem cristã, cumpre-se a máxima bíblica de que perante Deus não existe diferença entre povos, raças, tribos ou nações (Ap 5.9). 
A unidade e a universalidade são a mensagem religiosa na perspectiva cristã e de outros credos religiosos ou espiritualistas, nos quais se articula e vivencia-se uma práxis de relação de cuidado e amor com o próximo, atenção e fraternidade. Isso faz que a religião seja uma ponte entre as nações, e não mais uma barreira que divide povos. A mensagem pentecostal trazida pelos missionários assembleianos estava pautada nesse conceito de religião, como algo necessário e que coopera com uma mudança social e pessoal na vida de todos que creem no ensino promovido pelos pregoeiros dessa doutrina.

A religião na vida das pessoas é uma questão histórica e considerada por autores uma necessidade de sentido.

\begin{abstract}
Pelo lugar ocupado na vida das pessoas e da sociedade pelas questões relacionadas com a vida cotidiana é que elas necessitam de sentido. Como afirmam Berger e Luckman (1976, p. 35), "a vida cotidiana apresenta-se como uma realidade interpretada pelos homens e subjetivamente dotada de sentido para eles na medida em que forma um mundo coerente". É aí que entra a religião (LEMOS, 2012, p. 124).
\end{abstract}

Esse sentido trazido pela religião perpassa toda a história de vida do indivíduo e o leva a pensar, considerar e agir com perspectivas que estão entrelaçadas com fé, amor e práticas fraternas, proporcionando, assim, esse mundo mais coerente, como cita a autora, na busca de uma realização ideal e de sentidos na vida das pessoas.

Como considera Heller (1998, p. 168 apud LEMOS, 2012, p. 124), "a religião, ainda que mediante conteúdos e intensidades diferentes em suas diversas formas, constitui um dos organizadores e reguladores e, com frequência, um dos mais importantes, da vida cotidiana". Essa importância da religião na história de vida dos praticantes e crentes de qualquer grupo religioso ou espiritualista é marcada por práticas de superação e transformação do mundo.

Essa mensagem é presente no discurso assembleiano, baseado na Bíblia. Segundo "Atos 2", os membros da comunidade tinham tudo em comum e a igreja primitiva marcava seu tempo por gerar transformação onde se estabelecia. Além de cuidar de todos que "se salvavam" no seio da igreja, expandia a mensagem de amor de Cristo nos trabalhos missionários dos apóstolos e primeiros cristãos (At 2.44).

É papel da igreja agregar o migrante ao seu grupo social e acolher aquele que está longe de seu lugar de origem, mas que, ao mesmo tempo, continua na sua casa, que é a Terra, onde todos são irmãos. Cabe aos membros da igreja tratar com amor e cuidado aqueles que escolheram viver, sonhar e construir uma vida no Brasil, ainda que não tenham nascido aqui.

A questão do migrante deve ser considerada e pensada a partir de princípios éticos, de amor à vida e do cuidado com o outro, pois, se não houver assistência, o migrante acaba tornando-se um profissional de deslocamento e de mudança, mudando de um lugar para o 
outro e não conseguindo se estabelecer em nenhum lugar. Considerando algumas características novas da migração, pesquisadores afirmam que:

Há indícios de movimentos contínuos, sem nítida área de destino; ou seja, os deslocamentos se sucedem em múltiplas tentativas, com considerável migração de retorno, ou prosseguimento para outras áreas, configurando a significativa expressão de "migrante profissional" (PATARRA, 1983, p. 48).

0 mundo pentecostal assembleiano pode contribuir muito com o cuidado com os migrantes, trazer a cada homem, mulher e criança uma mensagem de esperança e libertação, não apenas pela pregação, mas por atos de acolhimento e apoio ao que migra de uma terra e vem para o Brasil ou outro país em que esteja presente a Igreja AD. Fazer isso é viver o Pentecostes, que une, acolhe e festeja a alegria entre os povos que creem que todos e todas somos irmãos e filhos de uma Divindade que ama o mundo, segundo o texto do evangelho (Jo 3.16).

A missão da lgreja, além de suas perspectivas institucionais, denominacionais e até mesmo doutrinárias, é vivenciar o objetivo de construir um mundo melhor e mais justo, abraçando o migrante e, assim, construindo uma sociedade unida pelo amor.

As caracteristicas desse "mundo melhor" apresentadas por Francisco, como é possivel observar, trazem na sua lógica a denúncia de tudo que impede a sua realização. Desta forma, na sua primeira mensagem sobre o Dia do Migrante e do Refugiado, o posicionamento do Papa não só aponta para a necessidade de mudanças sociais - nacionais e mundiais - que alterem significativamente o modo como os migrantes são tratados, mas também recorda à Igreja que esta é "chamada a ser o Povo de Deus que abraça todos os povos, e leva a todos os povos o anúncio do Evangelho, pois no rosto de cada pessoa está estampado o rosto de Cristo". Segundo Francisco, para a Igreja a realidade dos migrantes e refugiados é oportunidade para que a comunidade cristã contribua com a construção de uma sociedade mais justa e fraterna (SANCHEZ, 2018, p. 333).

A transformação do mundo é uma missão de cada ser humano, porém o trabalho desenvolvido pelas instituições, sejam religiosas, políticas, sociais, financeiras, educacionais ou de qualquer área, é de fundamental importância para a unidade, o desenvolvimento e a justiça tão almejados. A AD é uma instituição que nasceu a partir do trabalho de migrantes que, vivendo no Brasil, "deram as mãos" aos brasileiros e somaram forças para implantar sua obra de evangelização, que, além da mensagem religiosa, teve imensa contribuição histórica na promoção de mudança e libertação social.

0 mundo tem enfrentado crises econômicas, políticas e sociais, mas as principais crises são as condutas antiéticas, desumanas e que incentivam o preconceito e dividem seres 
humanos. E a xenofobia, ou o preconceito contra imigrantes, é uma das piores práticas dos atos desumanos e incoerentes praticados por pessoas, povos, governos propagados por ideologias e perspectivas políticas como o neofascismo e neonazismo.

\section{CONSIDERAÇÕES FINAIS}

Os missionários que fundaram a AD vivenciaram na pele as perseguições por serem estrangeiros e foram vitimas de preconceito nas localidades onde implantaram uma nova congregação e, menos de duas décadas depois, sofreram preconceito por alguns obreiros brasileiros, que, além de demonstrarem o desejo de se separarem dos missionários, ainda buscavam exercer controle sobre as igrejas, fruto de um anseio político nacionalista que reinou nessa época.

$\mathrm{Na}$ atualidade, ideias xenófobas têm encontrado espaço em igrejas e espaços religiosos com mais frequência. Sendo que, incentivados por conteúdos e políticas nacionalistas com bases neofascistas, incentivam ideias de fechamento de fronteiras para barrar a entrada de estrangeiros e o não acolhimento dos irmãos que migram de outras regiões do globo para o Brasil, desprezando, assim, os ensinamentos da fé que professam e o testemunho histórico da Igreja a que pertencem.

A construção histórica da AD é a partir de estrangeiros, não por europeus ou americanos ricos, mas, sim, por pobres, que nada tinham quando aqui chegaram e nada levaram quando partiram ou faleceram em terras brasileiras. Foram homens e mulheres que marcaram uma geração por amarem os brasileiros e os imigrantes que aqui também encontraram, e por viverem o Pentecostes na sua maior essência, a unidade de povos e nações.

Mesmo havendo pessoas que agem de forma incoerente com os estrangeiros, existe uma grande quantidade de pastores que, incentivados pela história da lgreja, decidiram cumprir a missão do Ide e iniciaram o envio de missionários e a organização de secretarias de missões em âmbito estadual e nacional, para, juntos, realizarem o propósito e a ordenança da evangelização mundial.

0 tempo passou e, mais de 100 anos após a fundação da igreja pentecostal no Brasil, crises migratórias ainda existem no país, que, nos últimos anos, recebeu muitos haitianos e venezuelanos. Contudo, tendo em vista sua missão de cuidar e acolher pessoas, muitas Assembleias de Deus têm acolhido homens e mulheres vindos desses paises. Esse trabalho dos assembleianos no acolhimento dos migrantes do Haiti e da Venezuela pode ser tema de futuras pesquisas.

Por fim, este trabalho busca conscientizar líderes e membros assembleianos, bem como a população evangélica e não evangélica, de que a história da Igreja é de acolhimento de todos, valorizando e apregoando a importância da vida fraterna da população mundial em unidade, incentivada pelo espírito de amor e unidade do pentecoste e da Igreja. 
Tratando-se da Igreja Pentecostal AD, desde sua origem, organização e atuação, tem em seus anais a marca e a influência estrangeiras, que aqui apenas acrescentaram e ajudaram a organizar o trabalho assembleiano, da fundação até os dias de hoje. A Igreja Assembleia de Deus só existe pela chegada de estrangeiros que ensinaram, escreveram e apregoaram que eram cidadãos do reino celestial, onde raça, cor, língua ou costumes não os impediam de viver em paz com os seus irmãos e irmãs.

\title{
Migration and mission in the Assembly of God in Brazil: from swedish missionaries to brazilian missionaries, a migratory journey in assembly pentecostalism
}

\begin{abstract}
The present work seeks to present how migration has always been part of the history of the Assembly of God Church in Brazil, through an introduction of the historical path of the largest Pentecostal denomination in the world, bringing a brief report of the coming of Swedish missionaries to Belém, Pará, and the arrival of other workers from other nationalities to cooperate in the mission of the implantation of the Assembly of God in other states and in the interior of the northern region of the country and in the sending of Brazilian missionaries to other nationalities in order to fulfill the great commission. We accomplished, thus, a historical and sociological analysis of the migration presence in the Pentecostal environment until the contemporaneity, because by means of these historical fundaments the bases for the contemporary work of the Assemblies missions present in all the corners of the world were built. This research has its importance for presenting to the leaders, members of this denomination, students and researchers, a greater understanding about the subject of migration. This is fundamental for the appreciation of each person who leaves his homeland and migrates to another country for various reasons and to raise awareness about the conduct of the host, which should always be based on the welcome, understanding and support, because all groups have marks of migration in their historical journeys.
\end{abstract}

Keywords: Migration. Missionaries. Assembly of God. Pentecostalism. Migrant.

\section{REFERÊNCIAS}

ALENCAR, G. Assembleia de Deus: origem, implantação e militância (1911-1946). São Paulo: Arte Editorial, 2010.

BÍBLIA Sagrada. Tradução João Ferreira de Almeida. rev. atual. Barueri: Sociedade Bíblica do Brasil, 2011. 1.280 p.

CONRAD0, C. Histórico da Secretaria Nacional de Missões da Assembleia de Deus no Brasil. Destinatário: [Jimmy Barbosa Pessoa]. [s. I.], 13. jun. 2019. 1 mensagem eletrônica.

COSTA, L. C. A.; MELLO, L. I. A. de. História do Brasil. São Paulo: Scipione, 1999. 
DANIEL, S. História da Convenção Geral das Assembleias de Deus no Brasil. Rio de Janeiro: CPAD, 2004.

LEMOS, C. T. Mobilidade religiosa e suas interfaces com a intimidade e a vida cotidiana. In: OLIVEIRA, P. A. R. de; MORI, G. de. Mobilidade religiosa: linguagem, juventude, política. São Paulo: Paulinas, 2012. p. 119-142.

PATARRA, N. L. Movimentos migratórios: características e tendências recentes. In: CENTRO DE ESTUDOS MIGRATÓRIOS. 0 vaivém da sobrevivência. São Paulo: Paulinas, 1983. p. 47-64.

SANCHEZ, W. L. Francisco e as migrações: um olhar a partir das mensagens para o Dia Mundial do Migrante e do Refugiado. Perspectiva Teológica, Belo Horizonte, v. 50, n. 2, p. 325342, maio/ago. 2018.

VINGREN, I. Diário de um pioneiro. Rio de Janeiro: CPAD, 2017. 